\title{
New trends in HR technologies: overview of foreign studies
}

\author{
Natalia Yu. Sinyagina ${ }^{1 *}$ \\ ${ }^{1}$ RANEPA, Faculty of Evaluation and Development of Managerial Human Resources, Research \\ Laboratory of Diagnostics and Assessment of Managers, the Graduate School of Public \\ Administration, Moscow, Russia
}

\begin{abstract}
The main aim of this work is theoretical studies of trends in HR technologies based on foreign and Russian publications and practice. This article highlights the most obvious trends of working with talented employees supported by attitude to talented persons, the analysis of various types of attitudes to them is performed; it is mentioned that positive attitude at present is one of the most important properties demanded by employers, since quite often it adds positive properties to a working team. The data were collected, classified and generalized using theoretical analysis, content analysis, and analytical synthesis of more than 50 scientific publications by researchers and practitioners from Australia, Great Britain, Germany, Russia, and the USA. This article presents the most significant results of the study. The trends of shifting the focus from equality in the relation to employees to fairness and the importance of fitting the culture of relations into the corporate culture are characterized. Generalized typology of talented employees is presented. The reasons of talented employees for leaving the company are analyzed. The importance of evaluation of skills to communicate with people, to find compromise is described, as well as of skills required for execution of this or that activity. Necessity of long-term well-considered relations with people, who are at the top in their working area, is mentioned.
\end{abstract}

Keywords: trends in HR technologies, management of talents, trends, attitude.

\section{Introduction}

Nowadays the management of talents is the most discussed topic in all spheres of governmental management, production and business, since it is commonly recognized that this is a decisive factor of success in the industries where qualified persons are highly demanded. Competition for the best management staff is being intensified, HR service requires for new approaches and innovative strategies of development of talents based on corporate culture, its unique properties considering for world trends in HR technologies. The objective of this article is to analyze theoretically such trends in foreign and Russian science and practice.

\footnotetext{
*Corresponding author: nsinyagina@yandex.ru
} 


\section{Methods}

The attitude to talented persons in society is ambiguous. In the previous works, the authors mentioned that in the Russian society there prevailed dual attitude to talented persons: on the one hand, careful (about $60 \%$ of citizens believed that they were national treasure and should be protected), and on the other hand, incredulous and dismissive [1]. The latter trend is quite popular in the world. According to L. Kronborg (Monash University, Australia), such attitudes are inherent not only to public but also to some researchers, who try to decrease the significance of the role of talented people in civilization development [2]. According to Church et al. [3], only one third of employees receive information that they are talented for their company and loyal to it, thus, most such experts look for employment by other company. In addition, the criticism of studies in the area of talent management is that the ways to preserve their quality and quantity were not proposed (Vaiman, Collings, Scullion) [4].

These main trends motivated this study, making relevant necessity to analyze initiatives in the field of HR technologies, which agreed with the authors' basic concepts. The main methods were as follows: theoretical analysis and synthesis of more than 50 publications by researchers from Australia, Great Britain, Germany, Russia, and the USA, as well as their typology and generalization. The method of analytical induction played an important role and contributed to total data analysis, whereas the theory based on constructivism promoted their operationalization. This article presented the most significant experimental results.

\section{Results and discussion}

As mentioned above, in science and HR practice there exist different attitudes to working with talents. At the beginning of the century, the active trend was fair attitude to employees, maintaining equality [5]. Then the focus was shifted from the equality regarding employees to fairness at working place. S. Spiegel [6] mentions that HR managers frequently speak about equality at working place: equal attitude, equal salary, equal opportunities for promotion, mentioning that despite the importance of it, the employees look for and appreciate in the company, first of all, fairness, believing that exactly the fair attitude influences the creation of favorable working environment. Representatives of this trend believe that fairness, being a new policy in HR activity, is more important than equality at working place.

In recent years among HR managers there are more and more supporters, believing that together with fairness and equality one more factor should be considered: attitude [7]. The researchers of the Michigan University demonstrated that a solid team was more efficient in its activity than the team with failed relations [8]. More than $36 \%$ of professionals, interviewed on Linked-In, have agreed that positive attitude at present is one of the most important properties looked for by employers, since it contributes positive properties to the team, such as spirit of cooperation, detachment, and flexible approach, promotes formation of responsibility [9]. According to the supporters of this approach, in order to disclose, whether the applicant for the position has the ability to get along with people, to find compromise and has skills required to perform his duties, his personality should be analyzed more attentively, including his manner to talk on phone, write e-mails, communicate personally. The Linked-In experts believe that nearly $89 \%$ of employees, who leave the company, are dismissed due to improper attitude, propensity to conflict, and inability to organize constructive business communication [9]. Herewith, it turns out that for many companies, training good relationship skills is less expensive than loss of qualified and talented, but irritable or negative employees. Therefore, companies are ready to spend money for arrangement of special educational programs, trainings, etc. 
D. Anderson in How to Handle a Successful Employee with a Bad Attitude [10] also believes that highly efficient worker with bad attitude can do more harm than good, and the achieved results, most probably, would introduce numerous problems. The author proposes the portraits of employees, who would be the most useful for the company:

- "team player": an ideal employee, focused on teamwork, never playing the "not my job" card;

- "honest and responsible": a person with a responsible character, able to admit his/her mistakes and learn from his/her own experience, never blaming others;

- "proactive": capable of doing work that is not his/her responsibility;

- "mentor": an experienced professional, always ready to give advice to colleagues. Never acts as if he/she is more important than someone who is younger or less experienced;

- "positive": a friendly, approachable person who brings a positive attitude to the team.

The described portraits, according to the author, represent a talented employee, required for the company; thus, it is proposed to specially control the attitudes of each employee, regularly reminding that the objectives are efficiently achieved when different people work good together.

On the Hiremetrix website [11], its founder writes that the society pays too much attention to talents, trying to explain, how people reach success, who becomes more successful, mentioning that there exists real danger of influence of this attitude to them. The author believes that the attitude to talented persons depends on how they think about something, how they behave with others, how they treat various challenges, make decisions, and, referring to his research, mentions that the talent plays significantly lower role in success in comparison with behavior with others, mostly colleagues.

The talented persons describe the attitude of loved ones and public. "My family due to my intelligence treated me as a strange..."; "Even my wife considers me 'white inside', though believes that I am genius, and my colleagues consider me as a threat or a monster"; "Corporate American society considered my intelligence as a tool, which could be called someone else's prize"; "In childhood I was treated as a person, who should be broken, and only in primary school everything was OK with most teachers... Some of the most modern teachers really liked me. However, the mistress of the school was always picking on me: "you do not need brains to cut fingernails and to wash dishes"; "If you are much cleverer than others, just be quiet" my classmates used to tell me, mocking, because I was the cleverest child in the school" (Examples are taken from various American forums and blogs, 20192020).

David R. Holt [12] mentions that, as a rule, people respect true intelligence; however, peculiar skill to please others is, nevertheless, required from the talent. The researcher believes that if a person has good knowledge in certain subject or subjects, and only flaunts them boastfully, then, it is unlikely that he uses this knowledge in a wise or reasonable manner, and the only respect that he will receive is the surprise of less educated people, whereas in this case, more desirable is the respect from equal persons. The way how a person treats his knowledge determines his intelligence, his attitude to society, to other talented persons. It should be considered that persons with lower level of intelligence are dull for those with higher level; hence, such people are less compatible, and thus, a talented person should accept the estimate by equal persons, since it is adequate [12]. Such position is the most popular among the HR managers looking for talents and working with them.

Nowadays the competition for the best talents is still continuing, the lack in skills of this process is obvious. For instance, an engineering company, which is looking for developers, can need general strategy to develop talents based on their internal corporate culture, unique advantages, as well as enhancement and use of own brand. Hiring managers and recruiters can improve general hiring scheduling, provided that the company has basic understanding of strategic character of hiring talents [13]. D. Turner, manager of the fast-food restaurant 
chain Chick-fil-A, believes that all industries should focus on attracting talents and not on staff employment, since such hiring creates a stronger company, promotes team working and improves efficiency [13].

\section{Conclusion}

In the existing competitive environment, all markets of talents require substantiated modern talent acquisition strategy, which, being an important part of their searching and employment, would promote creation of the best team and improvement in working efficiency. Aiming at this, the companies, which seriously consider their long-term future, purposefully arrange the links and construct relations with people, who are at the top in their working area.

\section{References}

1. N.Yu. Sinyagina, Upravleniye talantami: v poiske effektivnosti [Talent management: in search of performance], in Proceedings of the Conference "Teoriya i Praktika Psikhologicheskogo Soprovozhdeniya Rukovodyashchikh Kadrov" [Theory and Practice of Psychological Support for Leading Personnel], 17 April 2019, Minsk, Belarus, 56-61 (2019)

2. L. Kronborg, Gifted education in Australia and New Zealand, in S. I. Pfeiffer, E. Shaunessy-Dedrick, M. Foley-Nicpon (Eds.), APA handbooks in psychology®. APA handbook of giftedness and talent, 85-96 (American Psychological Association, Washington, DC, 2018). https://doi.org/10.1037/0000038-006

3. A.H. Church, C.T. Rotolo, N.M. Ginther, R. Levine, Consult. Psychol. J., 67, 17-47 (2015). https://doi.org/10.1037/cpb0000030

4. V. Vaiman, D.G. Collings, H. Scullion, Journal of Organizational Effectiveness: People and Performance, 4(4), 294-297 (2017). https://doi.org/10.1108/JOEPP-122017-070

5. HR.com, Treat employees fairly but not equally (2003). Accessed on: December 10, 2020. [Online]. Available: https://www.hr.com/en/communities/labor_relations/treatemployees-fairly-but-not-equally_ead01v2a.html

6. S. Spiegel, Why employees don't want to be treated equally: They want to be treated fairly. Crewhu (2018). Accessed on: December 10, 2020. [Online]. Available: http://www.crewhu.com/blog/why-employees-dont-want-to-be-treated-equally-theywant-to-be-treated-fairly

7. AKKA Architects, Attitude: The number one factor when hiring new employees. Akka Architects website (2020). Accessed on: December 12, 2020. [Online]. Available: https://www.akkaarchitects.com/attitude-the-number-one-factor-when-hiring-newemployees/

8. E. Seppälä, Positive teams are more productive. Harvard Business Review (2015). Accessed on: December 12, 2020. [Online]. Available: https://hbr.org/2015/03/positive-teams-are-more-productive

9. A positive attitude at work can be the key to your success. Resume target blog (n.d.). Accessed on: December 12, 2020. [Online]. Available: https://www.resumetarget.com/blog/a-positive-attitude-at-work-can-be-the-key-toyour-success/ 
10. Dave, How to handle a successful employee with a bad attitude. Trakstar (2018). Accessed on: December 12, 2020. [Online]. Available: https://www.trakstar.com/blogpost/handle-successful-employee-bad-attitude/

11. P. Michael, Talent vs Attitude: Who are the most successful graduates? Hiremetrix blog (2015). Accessed on: December 12, 2020. [Online]. Available:

https://www.hiremetrix.com/blog/post/talent-vs-attitude-who-are-the-most-successfulgraduates-

12. D.R. Holt, How does society treat you for being "intelligent"? Do people treat you differently? Quora (2018). Accessed on: December 11, 2020. [Online]. Available: https://www.quora.com/How-does-society-treat-you-for-being-intelligent-Do-peopletreat-you-differently/answer/David-R-Holt

13. Jobvite, What is the difference between recruitment and talent acquisition?, Jobvite Blog (2016). Accessed on: December 15, 2020. [Online]. Available:

https://www.jobvite.com/recruiting-process/what-is-the-difference-betweenrecruitment-and-talent-acquisition/ 